\title{
Palliative Sedation in a Regional Paeditric Unit: Frequency of Practice, Characteristics of Patients and Sedation
}

I De Noriega Echevarría, M Rigal Andrés, A Navarro Mingorance, V Puertas Martín, MA Pérez Martín, L Martín Jiménez, R Martino Alba

Paediatric Palliative Care Unit of Madrid, Hospital Infantil Universitario del Niño Jesús

INTRODUCTION

Palliative sedation (PS) is used to avoid suffering due to refractory symptoms. However, data regarding it's rate of application, characteristics and risk factors in the paediatric population is still scarce.

\section{METHODS}

Type of study: Retrospective descriptive study based on clinical records.

Popullation: Deceased patients attended by the Paediatric Palliative Care Unit of Madrid (PPCUM) in a 5 year period (Jan 2013-Dec 2017).

\section{RESULTS}

Rate of application of PS $(n=163)$

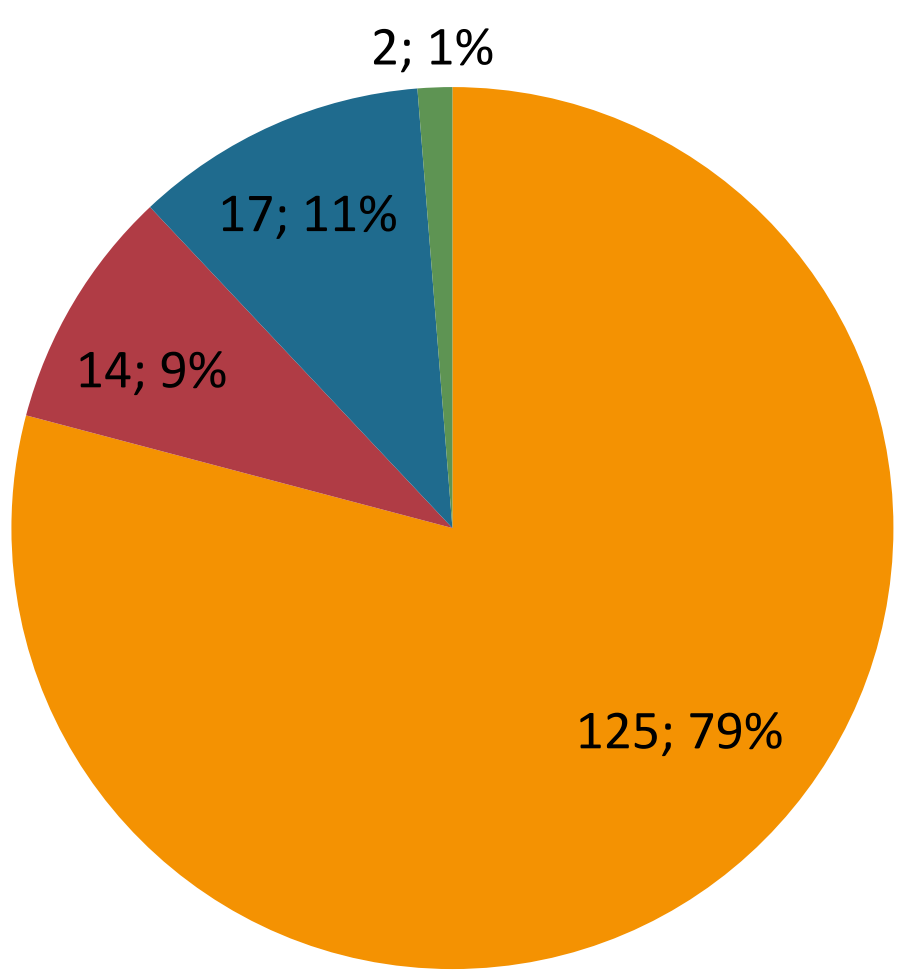

No. No need of PS.

No. Possible indication.

Yes. applied by PPCUM

Yes. other units

\section{Drugs used for the application of PS}

Midazolam
Midazolam + Haloperidol
Midazolam +Propofol
- PPF

Without data

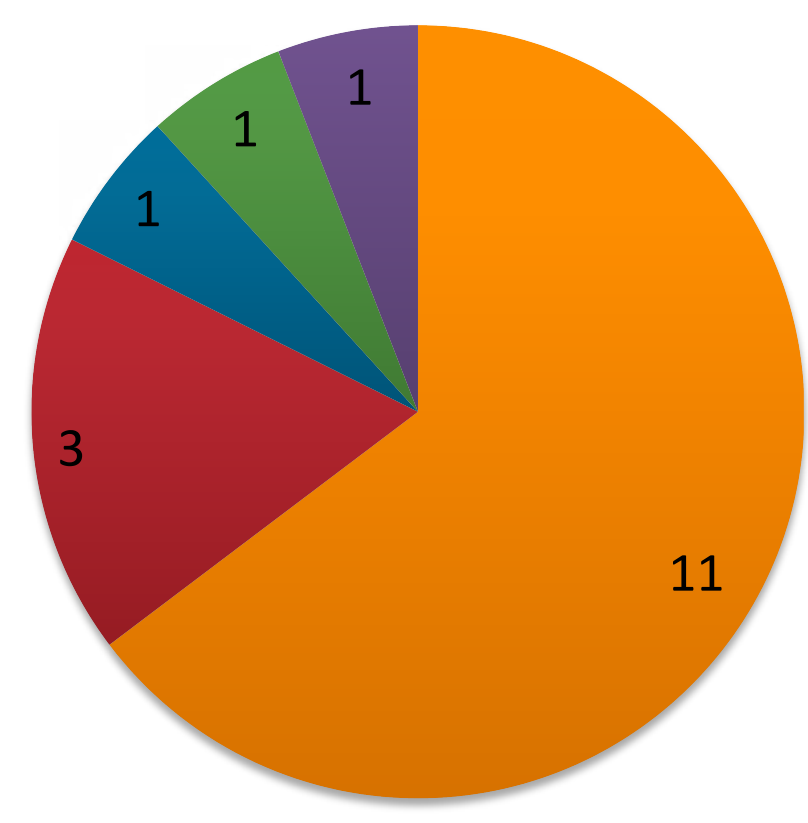

Patients that recieved PS by the PPCUM $(n=17)$

Gender: Males 12; Females 5

Age: $12 \pm 6$ years

Duration of PS: Mean 1 day (IQ 1-3,5)

Location at death: Hospital 9; Home 8

Type of disease

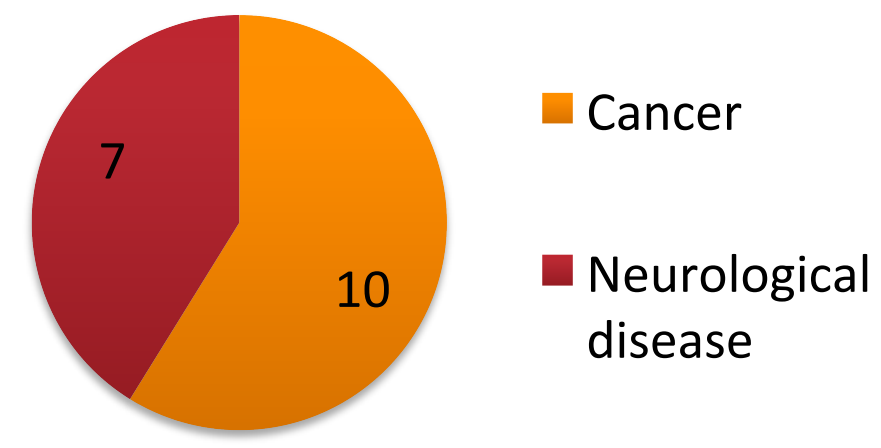

No difference was found for any variable except for location at death.

Dying at the hospital was signifficantly associated with recieving $P S(R R=2,1 ; p=0,04)$.

Symptoms for which PS was applied

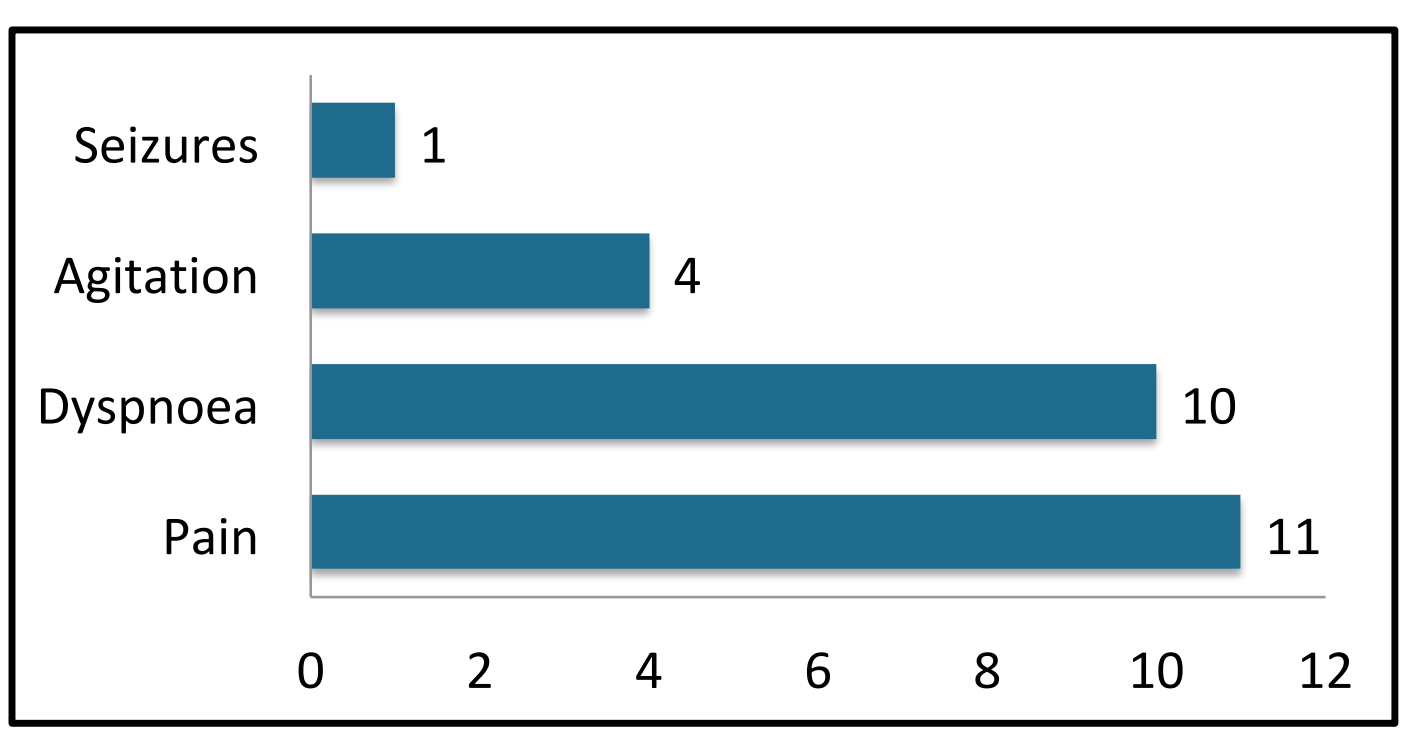

\section{CONCLUSIONS}

PS was applied in $11,7 \%$ of the patients.

Dying at the hospital was associated with a greater application of PS $(R R=2,1)$. No differences were found for gender, age or type of disease

The most frequent symptoms were pain and dyspnoea.

Midazolam was the drug used most frequently, alone or in combination. 